\title{
The Production and Motivation Mechanism of Sports Cultural Memory Space in Urban Greenway
}

\author{
Feng Qinhui $^{1}$, Wang Weiqiang ${ }^{1}$, Allam Maalla ${ }^{1 *}$ \\ ${ }^{1}$ Guangzhou College of Commerce, Guangzhou, China, 511363
}

\begin{abstract}
To study the relationship between urban greenway cycling space perception and cycling behavior intention, factor analysis, correlation analysis, and regression analysis were used to conduct a questionnaire survey of 411 college students to discover the advantages and disadvantages of urban greenway cycling factor, to achieve the comparison of related indicators and dimensions. The results show that the dimensions of Guangdong urban greenway sports space perception include accessibility perception, supporting perception, service perception, and environmental spatial characteristics; Guangdong college students' greenway cycling space perception is highly correlated with cycling behavior intention, and there is a positive correlation. Among them, the environmental spatial characteristics are the most influential factors. Greenway accessibility, supporting services, cycling landscapes, etc. can stimulate college students' greenway cycling behavior intentions. Improving the perception of urban greenway cycling space is an effective strategy to improve college students' greenway sports behaviour and greenway cycling behaviour.
\end{abstract}

\section{Introduction}

Early foreign countries put forward insights from the types of greenways, development stages, and greenway planning strategies. The "Emerald Necklace" in Boston is a display form of greenways in the United States and is an important material for my country's early understanding of greenways[5-7]. The initial greenway construction in the United States was due to a one-month long-distance route exploration and cycling by 10 cyclists on the east coast of the United States. The greenway plan was supported by relevant departments and the Open Space Research Institute [8], which connected 15 Greenways in 450 cities and towns in the state have strategically expanded the safety of cycling [9]. In the foreign research on greenway riding experience, one is to pay attention to the greenway environment as a part of bicycle riding and combine personal experience with social experience [10]. The other is the research that focuses on the landscape perception and satisfaction of greenway cyclists. With the changes in greenway landscapes in urban areas, suburbs, and villages, the satisfaction of greenway users has been correspondingly improved, which has affected the greenway to a certain extent Service level satisfaction [11]. Foreign quantitative or qualitative research on greenway riding experience mainly focuses on the external experience of greenway cyclists and lacks internal psychological perception research. Individual greenway riding research involves research on the internal perception of greenway riding and lacks relevant research. The analytical framework or theoretical basis for this is not sufficient. Domestic cycling research is mainly about cycling culture, shared bicycles, development history, cycling equipment, cycling equipment, cycling services, and spatial characteristics of cycling. Cycling enthusiasts mainly use the shortest distance of the road for longdistance sports to pursue the speed experience of cycling [12]. Greenway cycling research in my country is in its infancy. The main research includes greenway cycling's leisure benefits and happiness, greenway scenic spots, and cycling satisfaction research [13][14], but it ignores targeted greenway riding Empirical research and shortdistance greenway riding demand research, lack of the spatial distribution characteristics of greenway riding demand and greenway riding landscape perception research. As an open space, the urban greenway cycling space is a combination of the city and nature, and at the same time reflects the uniqueness of the urban greenway landscape

\section{Research Design}

\subsection{Questionnaire Design}

This study uses a self-compiled questionnaire to conduct the survey. The survey content includes the perception of accessibility, service perception, supporting perception, environmental spatial characteristics, and behavioral intentions of urban greenway cycling. The scales were measured using Likert's 5-level scoring method. According to the literature, the urban greenway cycling space perception and behavior intention vector scale was designed. To ensure the reliability and validity of the scale, the scale was optimized and the first draft was formed

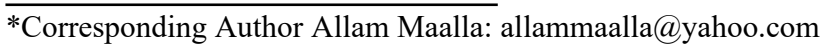


after soliciting the opinions of 5 experts to improve the appropriateness of the questionnaire. The research team conducted a predictive survey on the questionnaires before the large-scale formally distributed questionnaires. A total of 80 questionnaires were issued during the prediction phase, and 80 were recovered, of which 73 were valid questionnaires. The questionnaire's recovery rate and effective rate were 100 respectively. \% And $91.25 \%$. From the analysis results, the questionnaire has good overall reliability and validity, and it can better meet the needs of this research after revision.

\subsection{The internal structure of greenway cycling space perception and behavior intention}

Use SPSS20.0 software to perform item analysis on the prediction results to test the appropriateness of the scale items. The analysis results show that the $\mathrm{P}$ values of all items in Q1-Q43 are significantly different regardless of non-homogeneity of variance or homogeneity of variance. : Sig (two-sided) $<0.05$, all items in the scale are discriminatory and all are retained. Then, the internal structure validity and content validity of the questionnaire are analyzed through exploratory factors. Dimensionality reduction analysis was performed on 43 items. The results showed that the KMO value was $0.792(>0.7)$, and the approximate chi-square value of Bartlett's sphere test was $3328.438(\mathrm{df}=903, \mathrm{Sig}=0.000<0.05)$, indicating that the test questionnaire is suitable for factor analysis. Using principal component analysis, 8 factors were extracted, and items with only one or two questions on a level were deleted. After deleting the 7 items in the scale, to further understand the structural validity of the scale, factor analysis was performed again. The result showed that the $\mathrm{KMO}$ value was $0.850(>0.7)$, and the approximate chisquare value of Bartlett's sphere test was 2705.620 (df= 630 , Sig $=0.000<0.05$ ), summed up 5 factors instead of 36 questions. Finally, through the internal consistency test of the questionnaire, the remaining 36 items on the scale were distributed among 5 common factors, named according to the meaning of the questions, and reliability analysis was carried out. The results showed that: factor 1 green road riding can enter Sexy knowing (Cronbach's $\mathrm{a}=0.909$ ), factor 2 greenway riding supporting perception (Cronbach's a $=0.930$ ), factor 3 greenway riding service perception (Cronbach's $\mathrm{a}=0.856$ ), factor 4 greenway riding environment spatial characteristics (Cronbach's $\mathrm{a}=0.874$ ) and Factor 5 behavioral intentions (perceptions and preferences) for greenway riding (Cronbach's $\mathrm{a}=0.780$ ). The overall Cronbach's coefficient of the questionnaire is 0.972 , indicating that the questionnaire has high reliability

\section{Correlation Analysis Results}

Taking the perception of greenway riding accessibility, supporting the perception of greenway riding, service perception of greenway riding, and spatial characteristics of greenway riding environment as variables, the correlation between them and the behavior intention of greenway riding is analyzed. Pearson analysis of bivariate correlation was used for the two-tailed T-test, and the statistics were the mean and standard deviation. It can be seen from Table 5 that the significance probability level of the correlation coefficient between the four external perception factors perceived by the greenway space and the riding behavior preference is 0.01 . It can be seen that the perception of accessibility, supporting perception, service perception, environmental space, and environmental characteristics of greenway riding are closely related to greenway riding behavior preferences.

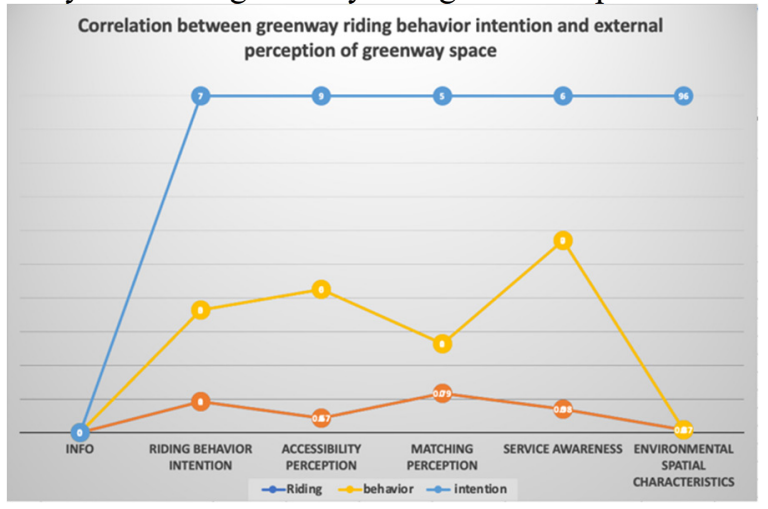

Fig. 1. Correlation between greenway riding behavior intention and external perception of greenway space

\section{Results of multiple linear regression analysis}

To study the direction and magnitude of the influence of greenway space perception on cycling behavior intention, a multiple linear regression model was established for analysis. When performing linear regression analysis, first determine whether there is a linear relationship between the dependent variable and each independent variable, and observe the accessibility perception, supporting perception, service perception, and environmental space environment characteristics of greenway cycling behavior intention and cycling space perception. Whether there is a linear relationship in the scatter plot, Figure 1 shows that the distribution between them has a linear relationship, and multiple linear regression analysis can be performed. The results show the R-square is 0.753 , which is greater than 0.5 . The R-square equation can explain $75.3 \%$ of the total variation, and the degree of explanation is high. It can be considered that the regression equation model fits well. The significance probability of the F value is 0.000 , and the values are all less than 0.001. The established regression model is statistically significant, and the regression equation passes the significance test. Among the regression coefficients, only the matching perception did not pass the significance test, and the accessibility perception, service perception, and environmental spatial characteristics all passed the significance test. Comparing the regression coefficients of the respective variables into the model, it is found that the perception of accessibility, service perception and environmental spatial characteristics have a strong influence on greenway riding behavior intention. Therefore, the result of multiple linear regression analysis is expressed as Greenway cycling behavior intention $=0.251+0.123^{*} \quad$ (accessibility 
perception) $+0.191 *$ (service perception) $+0.603 *$ (environmental spatial characteristics).

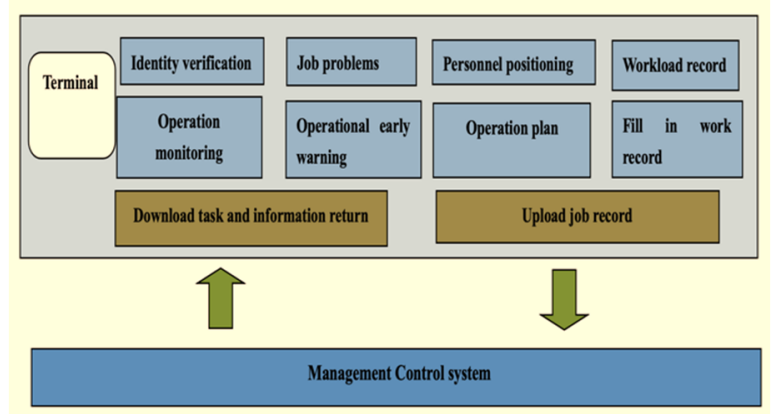

Fig. 2. Scatter diagram of four dimensions of green road riding behavior intention and spatial perception

The chronic network space of urban bicycle riding is characterized by multi-level and high mobility, and its behavior characteristics are closely connected with the environment, and there are many central nodes, which are consistent with the urban economic level distribution [20]. Urban cycling realizes people's cycling behavior and perception of greenway sports space. Greenway space environment is an important intermediary factor. Behavioral decision-making, in reality, is bounded and rational. It is easier to filter out other factors when perceiving the environment and being satisfied [twentythree]. People's subjective behavior decision-making originates from internal driving factors but is also affected by external physical space and environmental perception. Correlation analysis confirms that there is a correlation between greenway cycling space perception and behavior intention. Accessibility perception is positively correlated with cycling behavior intention $(\mathrm{r}=0.670)$. The distance between urban greenways and colleges is short, and the openness is good. The scale of greenway cycling can effectively promote the cycling group of Guangdong colleges and universities. Behavior, for example, students in Guangzhou University Town can reach the urban greenway when they go out, and they can reach the bioisland greenway in 5 minutes by cycling. The accessibility is strong, and the greenway for college students is large. The perception of supporting facilities is positively correlated with the intention of riding behavior $(\mathrm{r}=0.680)$. The supporting facilities for greenway riding are not only bicycle rental services, but also the guide signs for greenway riding, whether the road is level, the continuity of the greenway, and the connection whether it is comfortable or not has a good role in promoting the riding behavior of college students in Guangdong. Because the perception of greenway service is related to the intention of greenway riding behavior $(\mathrm{r}=0.745)$, the quality of sports service and physical fitness guidance in the urban greenway space is improved. Can promote the riding behavior of college students. It is not difficult to find out through field investigations of Guangdong urban greenway sports supporting facilities that the greenway cycling paths in the new urban area are spacious. For example, the newly-built greenways in Guangzhou Knowledge City only have slow-moving paths over 4 meters, but the greenway connections have a large gap.
And some drop more than $10 \mathrm{~cm}$, resulting in a very bad riding experience. There is a positive correlation between the environmental characteristics of the greenway space and the greenway riding behavior intention $(\mathrm{r}=0.835)$, and the attraction of the environmental space cannot be ignored. For example, the Huguangyan Scenic Spot in Zhanjiang attracts many nearby college students to ride around the lake on weekends, and Chaozhou's Hanjiang Greenway Scenic Area is also a choice for college students to ride. In addition to the greenway scenic area, greenway vegetation, greenway quality, greenway flatness, greenway rest facilities, greenway sanitation facilities, and greenway safety have the greatest influence on the riding behavior of Guangdong college students. Therefore, spatial perception is the internal driving force of cycling behavior intention and the most important factor in promoting greenway cycling among college cycling groups. It is true that from the current urban cycling activities, students riding on behalf of the young force triggers urban shared bicycles to become a major urban problem. Guangdong's urban greenway bicycle system is mainly based on recreational cycling lanes and commuter lanes. During weekends, urban greenway cycling will experience "vehicle jams". The greenway channels available for cycling are relatively narrow and the greenway is slow. Sports space planning has not been resolved for a long time, which will have a certain impact on urban greenway cycling [21]. Even in the face of the more attractive cultural landscape of the old city, the interest and enthusiasm for greenway cycling will decline. Based on this, the greenway cycling space perception indirectly affects college students' greenway cycling investment, focusing on the humanized design and reasonable planning of the slow-moving greenway space, and connecting the city's various scenic spots and cultures in the form of a greenway as a "necklace" Legacy, to give young people more greenway riding options, make up for the unfavorable factors of urban greenway, promote college students to have a higher level of low-carbon and fashion awareness of greenway riding, and help college students get better greenway riding Behavior intention, enjoy the fun of riding on urban greenways.

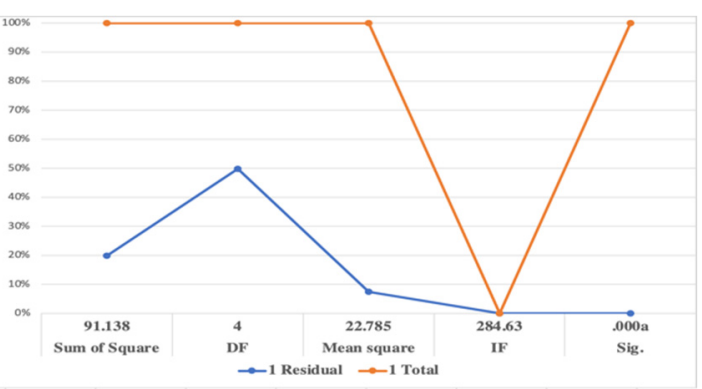

Fig. 3. Model summary

The research results further confirmed that urban greenway spatial perception can positively predict greenway riding behavior, and indirectly affect college students' investment in riding. Optimizing the accessibility, supporting facilities, and serving the environment of urban greenways is an important way for college students to invest in cycling behavior. The 
mechanism may be: the creation of greenway environmental space can drive college students to actively participate in greenway cycling through the novelty and diversity of the landscape, and quickly integrate their own cycling experience with greenway facilities and services by paying attention to demand adjustments, By quickly entering the greenway riding space to explore the perception of exercise, and then promote college students to more actively engage in greenway riding activities. In addition, this study also found that the dimension of greenway matching perception and greenway riding behavior intentions are not very significant. It may be that the spatial experience of the greenway is the most concern by the college cycling group.

\section{Conclusion}

The results showed that the KMO value was $0.792(>0.7)$, and the approximate chi-square value of Bartlett's sphere test was $3328.438(\mathrm{df}=903$, $\mathrm{Sig}=0.000<0.05)$, indicating that the test questionnaire is suitable for factor analysis. The usability and experience, publicity and convenience, performance, and sharing of Guangdong urban greenways meet the riding needs of college students and strengthen the individual design of the greenway space environment to create greenway riding behaviors that are conducive to college students. The deficiencies of this research still need follow-up improvement. The greenway channels available for cycling are relatively narrow and the greenway is slow. The viewpoints of this research have certain practical significance, meeting the psychological needs of urban greenway riding space can directly affect the behavior intention of college students in greenway riding.

\section{ACKNOWLEDGMENTS}

This research was financially supported by Guangdong Provincial Department of Education's Young Innovative Talents Project (Humanities and Social Sciences) Project name: "Strategies for improving physical fitness based on the physical fitness test of college students-Taking Guangzhou Business College as an example"; Project approval number: 2020WQNCX078, And Guangdong Province Project, Construction of Teaching Team in Guangdong Province's Colleges and Universities Project "E-commerce Teaching Team", (Project No. 2019SJJXTD01), And 2020 Guangdong Province Teaching Quality and Teaching Reform Project, Characteristic Majors, Data Science and Big Data Technology (Project No. 2020JTSZY01). And 2019 Guangzhou College of commerce Teaching Quality and Teaching Reform Project, Characteristic Majors, Data Science and Big Data Technology (Project No. 2019XJTSZY02). Corresponding Author Allam Maalla.

\section{References}

1. A. Maalla, "Development Prospect and Application Feasibility Analysis of Robotic Process Automation," 2019 IEEE 4th Advanced Information
Technology, Electronic and Automation Control Conference (IAEAC), Chengdu, China, 2019, pp. 2714-2717,

DOI: 10.1109/IAEAC47372.2019.8997983.

2. AHERN J. Greenways as a planning strategy[J]. Landscape and Urban Planning, 1995, 33(1/3):131155.

3. Li Guoyu. Greenway Sports and Happiness Guangdong [J. Journal of Physical Education, 2013(2): 39-43.

4. Qiu Jian. Exploration of urban commuting greenway design based on commuting travel behavior [D]. Ya'an: Sichuan Agricultural University.

5. 2017 China Cycling Sports Big Data Report. [EB/OL]. [2018-05-06]. http:/www.imxingzhe.com/document/344/,2018-56.

6. Little C E. Greenways for America[M]. Baltimore: Johns Hopkins University Press, 1990.

7. Ahern J. Greenways as a planning strategy[J]. Landscape and Urban Planning, 1995, 33(1-3): 131155.

8. Fabos J G. Introduction and overview: the greenway movement, uses, and potentials of greenways[J]. Landscape and Urban Planning, 1995, 33(1-3): 1-13.

9. Siderelis C, Moore R. Outdoor Recreation Net Benefits of Rail-trails[J]. Journal of Leisure Research, 1995, 27(4):344-359.

10. A. Maalla, "Research on DC Transmission Operation System Based on Analyze the Principle of Udi0," 2019 IEEE 4th Advanced Information Technology, Electronic, and Automation Control Conference (IAEAC), Chengdu, China, 2019, pp. 2580-2583,

DOI: 10.1109/IAEAC47372.2019.8997870

11. East Coast Greenway Alliance. About the alliance . [EB/OL]. [2013-04-25]. http://www.greenway.org

12. Deenihan G, Caulfield B, O’Dwyer D. Measuring the Success of the Great Western Greenway in Irelands[J]. Tourism Management Perspectives, 2013, 7: 73-82.

13. Lumsdon L, Downward P, Cope A. Monitoring of Cycle Tourism on Long Distance Trails: The North Sea Cycle Route[J]. Journal of Transport Geography, 2004, 12(1): 13-22.

14. Lu Xutao, Hong Pengfei. Research on Cycling Behavior and Spatial Features Based on Web Text Analysis [J]. Journal of Beijing Sport University, 2018(5): 32-38.

15. A. Maalla, "Current Status of Valve Base Electronics Equipment in DC Transmission System," 2020 IEEE 5th Information Technology and Mechatronics Engineering Conference (ITOEC), Chongqing, China, 2020, pp. 1809-1812, doi: 10.1109/ITOEC49072.2020.9141831.

16. Yu Yong, Tian Jinxia. A study on the relationship between riders' leisure involvement, leisure benefits, and happiness structure: Taking Zhaoqing Xinghu Bicycle Greenway as an example[J]. Tourism Tribune, 2013(2): 67-76. 
17. Yang Shu, Zhang Weiya. A study on the correlation between the perceived image of the scenic spot and the satisfaction of recreation: Taking the cycling recreationists on the Zijin Mountain Greenway as an example [J]. Resource Development and Market, 2014 (10): 1268-1273.

18. Hoffman DD, Singh M, Prakash C. The Interface Theory of Perception[J]. Psychonomic Bulletin \& Review, 2015(6): 1-27.

19. PRUYT E, ISLAM T. On Generating and Exploring the Behavior Space of Complex Models[J]. System Dynamics Review, 2016, 31(4): 220-249.
20. Cai Yujun, Zhou Peng, et al. The relationship between urban residents' perception of public sports space and sports activities[J]. Journal of Chengdu Sport University, 2018(4): 48-53.

21. A. Maalla, "Current Status of Valve Base Electronics Equipment in DC Transmission System," 2020 IEEE 5th Information Technology and Mechatronics Engineering Conference (ITOEC), Chongqing, China, 2020, pp. 1809-1812, doi: 10.1109/ITOEC49072.2020.9141831. 